\title{
Improving the Achievement, Motivation, and Engagement of Students With ADHD: The Role of Personal Best Goals and Other Growth-Based Approaches
}

\author{
Andrew J. Martin \\ Faculty of Education and Social Work, University of Sydney, Sydney, New South Wales, Australia
}

\begin{abstract}
In light of recent evidence suggesting the academic benefits of personal best (PB) goals for students with attention-deficit/hyperactivity disorder (ADHD), this article explores practical approaches to implementing PB goals in the counselling and classroom context. Beginning with a brief summary of how and why PB goals impact academic outcomes and the relevance of this to students with ADHD, concrete steps to implementing PB goals are described. Following this, the broader concept of academic growth is discussed, along with some guidance as to how to operationalise growth approaches with students. Taken together, a greater focus on academically at-risk students' personal trajectories is suggested as a potentially fruitful approach to enhancing their educational outcomes.
\end{abstract}

- Keywords: attention-deficit/hyperactivity disorder, ADD, ADHD, goals, engagement, achievement

\section{PB Goals and Students with Attention-Deficit/ Hyperactivity Disorder}

Goal-setting is important for students' academic development (Anderman \& Wolters, 2006; Elliot, 2005; Linnenbrink-Garcia, Tyson, \& Patall, 2008; Locke \& Latham, 2002; Maehr \& Zusho, 2009). One of the most recently proposed goal-setting strategies involves 'personal best' (PB) goals. PB goals are defined as specific, challenging, competitively self-referenced targets towards which students strive (Martin, 2006; Martin \& Liem, 2010). PB goal-setting involves focusing on one's own progress and achievement more than focusing on the progress and achievement of other students. It also involves trying to do a bit more or a bit better

ADDRess FOR CORRESPONDENCE: Andrew J. Martin, Faculty of Education and Social Work, A35 - Education Building, University of Sydney NSW 2006, Australia. Email: andrew.martin@ sydney.edu.au 
than previous efforts, each time important schoolwork such as a test or assignment is tackled. These growth-oriented goals are one application of recent emphases on growth and value-added approaches to educational development (see Anderman, Anderman, Yough, \& Gimbert, 2010; Betebenner, 2008, 2009; Briggs \& Betebenner, 2009; Dweck, 2006; Harris, 2011). Focusing on the individual and his/her personal progress, growth approaches are somewhat different from the more traditional static, snapshot, comparative, and norm-reference approaches. Indeed, this focus on the individual and his/her own personal progress aligns well with the student-centred work conducted by school counsellors and psychologists.

In the competitive context of today's classroom, students who struggle academically may be at particular risk of giving up due to difficulties competing as effectively as other students (Christenson, Reschly, \& Wylie, 2012). This struggle can be more pronounced in cases where students perceive that parents/caregivers, teachers, and more recently, government are placing pressure on them to perform competitively. On the other hand, when students compete against their own prior efforts, success becomes personally defined and potentially more accessible (Martin, 2012b).

In previous research, $\mathrm{PB}$ goals have been shown to enhance the academic outcomes of 'regular' high school students (Liem, Ginns, Martin, Stone, \& Herett, 2012; Martin, 2006; Martin \& Liem, 2010). However, if PB goals are to be implemented in diverse classrooms, it is important that they have positive effects across the diversity of students in those classrooms. For school counsellors and psychologists to implement $\mathrm{PB}$ approaches with referred students, it is critical that the concept and processes are widely applicable. In other words, it is necessary to ensure that psycho-educational constructs and interventions do not disproportionately advantage 'strong' students or disproportionately disadvantage at-risk students, thus leading to a widening of achievement gaps. To test for this, it is important to explore the effects of psycho-educational constructs and interventions to establish that there is educational yield for a diversity of students. In this article, the focus is on $\mathrm{PB}$ goals for students with attention-deficit/hyperactivity disorder (ADHD). Students with ADHD reside in most classrooms and so it is important to understand approaches to learning and instruction that help them achieve to their potential alongside their peers.

\section{Attention-Deficit/Hyperactivity Disorder}

ADHD is defined as 'a persistent pattern of inattention and/or hyperactivityimpulsivity that is more frequent and severe than typically observed in individuals at a comparable level of development' (American Psychiatric Association, DSMIV-TR, 2000, p. 85). Approximately $3-5 \%$ of children will be diagnosed (most of them boys), with approximately $50-70 \%$ persisting into adolescence (Barkley, 2006; Martin, 2012a; Purdie et al., 2002). Dominant psychological models of ADHD emphasise impairments to executive functioning and self-regulation. Four executive functions are often identified: verbal working memory, self-regulation of motivation, non-working memory, and reconstitution (Barkley, 2006). Together, these executive functions lead to self-regulatory control (Barkley, 2006). Cognate models of ADHD that emphasise cognitive and neuropsychological risk include the attentional neural network model of Swanson and colleagues (1998), the 
motivation inhibition model of Gray and McNaughton (2003), the executive function model of Brown (2005), the working memory model of Rapport, Chung, Shore, and Isaacs (2001), and the cognitive-energetic model of Sergeant (2005). There are also neuro-scientific and biochemical models that centre on reduced metabolic activity in frontal areas of the brain impacting inattention, impulsivity, and memory, and influencing abnormalities in neurotransmitter functioning responsible for the regulation of impulse control and attention (Barkley, 2006; Chandler, 2010).

Taken together, there are cognitive-behavioural, biochemical, and neurological factors specific to ADHD that are likely to impair academic outcomes (Martin, 2012a; Vostanis, 2007; Wilmhurst, Peele, \& Wilmhurst, 2011). Indeed, many of the tasks presented to children and young people at school require the very functions that ADHD seems to most impair. Consistent with this, for students with ADHD, there are greater rates of off-task behaviour, poor task completion, attention-seeking, and problematic self-regulation (Barkley, 2006; Vile Junod, DuPaul, Jitendra, Volpe, \& Cleary, 2006). Not surprisingly, there are markedly poorer outcomes on many academic indicators, including achievement, motivation, engagement, attainment and retention (DuPaul \& Stoner, 2003; Heiligenstein, Guenther, Levy, Savino, \& Fulwiler, 1999; Mariani \& Barkley, 1997; Purdie et al., 2002). This has prompted researchers to investigate factors that can assist the academic progress of students with ADHD (Martin, in press). Recently, PB goals have been explored as one such approach.

\section{What the Evidence Says about PB Goals and ADHD}

As noted above, a number of influential models of ADHD emphasise the selfregulatory aspects of the disorder. These self-regulatory actions comprise the executive functions required to successfully engage in tasks and activities, including schoolwork (Barkley, 2006). Because the executive functions of students with ADHD tend to be impaired, so too are the component functions related to goaldirected behaviour and goal-directed persistence. Thus, it has been hypothesised that students with ADHD who successfully engage in goal-directed behaviour and commitment will demonstrate positive academic outcomes.

A recent study by Martin (2012c) explored the role of PB goals among a group of students with ADHD compared with their non-ADHD peers in the same classroom. The study looked at the association between PB goals and academic achievement, motivation and engagement. It involved more than 3,400 Australian high school students and showed the positive role of PB goals in ADHD students' achievement, homework completion, planning, and persistence. It also found PB goals were associated with lower levels of academic disengagement. In fact, not only did PB goals benefit students with ADHD in achievement and engagement but in a number of cases the benefits of PB goals were greater for them than for non-ADHD students. Specifically, for some variables, there were stronger associations with PB goals for students with ADHD than their non-ADHD peers. This is a significant finding because if the benefits of $\mathrm{PB}$ goals are greater for students with ADHD, then $\mathrm{PB}$ goals may be one way to help close achievement gaps. For many students with $\mathrm{ADHD}$, it may not be desirable to focus too much on outperforming others. On the other hand, if they pursue PB goals and aim to beat their prior performance, 
this is a solid and accessible footing for academic growth. Further, the positive selfworth implications of students realising progress in their schoolwork have been demonstrated in prior research (Martin \& Liem, 2010).

\section{How Do PB Goals Work?}

There are a number of ways that goals are thought to work (Locke \& Latham, 2002) - and which may generalise to PB goals. First, PB goals provide specific information about what a student needs to aim for to outperform a previous best. Second, PB goals help students direct their attention and effort to the specific tasks that are essential to reach desired educational outcomes. This clarity and specificity is also helpful for student with ADHD. Third, trying to beat one's own previous benchmark tends to be seen by students as achievable and this builds confidence. Fourth, goals energise students and this increases effort. Fifth, PB goals create a gap between current and desired states; students are motivated to reduce gaps such as these. Sixth, there is a self-determined dimension to PB goals that enhances students' sense of autonomy and this is intrinsically motivating (see Ryan \& Deci, 2000, on self-determination theory). Finally, the combination of these factors increases the chances of success and this is vital for any subsequent success. There are sound reasons why $\mathrm{PB}$ goals may have positive effects for students and, in particular, be effective with at-risk students, including those with ADHD. Consistent with this, recent research has identified positive effects for students with ADHD through coaching for goal setting (Ratey \& Sleeper-Triplett, 2011).

\section{Selecting Process or Outcome PB Goals}

In determining the specific PB goal, it is important to understand that PB goals take two forms: process PB goals and outcome PB goals. Process PB goals refer to the activities that lead to one's performance on a particular task. For example, study effort would be a process that leads to performance on a test. In this case, the process $\mathrm{PB}$ goal would be to invest more effort for the next test than the previous test. Outcome PB goals refer to the results of the process in which one has engaged. For example, one's performance on the test would be an outcome that follows from the process of study effort. In this case, the outcome PB goal would be to improve on one's previous test result.

Other examples of process PB goals are:

- reading one more book for the present assignment than on the previous assignment

- preparing for a test at the weekend when previously no study had been done at weekends

- asking a teacher for help when previously the teacher had been avoided

- spending an extra hour doing homework compared with the usual time

- endeavouring to be less anxious in the upcoming test than in previous tests

- calling out in class fewer times today than yesterday

- staying in the seat longer in today's lesson than in yesterday's lesson.

Examples of outcome PB goals are: 
- getting a higher mark in end-of-year exams than in the half-yearly exams

- making greater reading progress than prior progress

- getting more sums correct in one's mathematics quiz.

It is important that students select a goal that is most timely and relevant to them at the present moment. In the beginning stages of goal setting, it may be helpful to focus on goals that are achievable in the immediate term, in order to give students an early sense of progress and confidence in the process and in themselves. For students with ADHD, it might also be helpful to focus on very concrete behaviours, as these are clearer to observe and monitor. In some cases, there may be incentives attached to meeting PB goals. There is growing research recognising that small and credible rewards administered at the right times can have positive effects on students' motivation (Covington, 2002).

Appendix A presents a PB Goals Worksheet (Martin, 2012b). The worksheet aims to integrate the various elements of PB goals and goal-setting outlined above.

\section{How to Set and Strive for PB Goals}

The steps involved in setting and achieving PB goals are as follows:

1. Understand exactly what a $\mathrm{PB}$ goal is and the difference between a 'process $\mathrm{PB}$ goal' and an 'outcome PB goal' (see above).

2. Understand how to set a PB goal that is appropriate: not too easy or difficult, achievable in a defined timeframe, relevant and timely for one's stage of academic development.

3. Set a specific PB goal.

4. Decide the timeframe in which it is to be achieved.

5. Write out the steps involved in working towards the PB goal.

6. Record and mark off each step as it is achieved, as this infuses the process with micro-successes.

7. Request help if any blockages occur midway through the steps.

8. Reflect on how well the PB goal was achieved and the possible reasons (that will be addressed next time) for not achieving the PB goal.

9. Set the next PB goal.

10. Closely monitor the student's progress throughout, particularly for academically at-risk students (e.g., those with ADHD).

\section{Other Growth Approaches}

Given the positive findings regarding PB (growth) goals for students with ADHD, there may be yield in considering additional growth approaches for these and other academically at-risk students. Consistent with Dweck's (2006) advice regarding the desirability of promoting and sustaining growth mindsets, other approaches considered here include learning growth, personal best (growth) indices, and achievement growth assessment. 


\section{Learning Growth}

PB goals tend to be focused on a specific and desirable outcome towards which the student systematically strives. One adaptation of this concept is to consider the learning process more broadly and to encourage students to consider growth in learning. This notion is aligned with recent developments in 'learning trajectory based instruction' (Sztajn, Confrey, Wilson, \& Edgington, 2012). Appendix B is one example of learning growth focusing on learning fractions in mathematics at the beginning of high school (Martin, 2012b). Here the student plots his/her growth in learning fractions, systemically moving to a position of mastery. Indeed, the teacher may adapt this chart to plot the classroom's growth in learning fractions on the white board.

\section{Growth Feedback Forms}

Another opportunity to integrate PBs and growth concepts into students' academic lives involves more effective use of feedback forms when returning work to students. Too often, assigned work is static and not connected to students' further improvement and academic development. Schoolwork they complete and submit for assessment is a vital learning growth opportunity and one not to be missed. In Appendix C (Martin, 2012b) is an example of a feedback form that crystallises the essential learning aims of assigned work, the criteria for assessment (including the extent to which the student has improved on previous work), strengths in the student's work, and specific areas for improvement. This form is completed by the teacher. In the second part of the form are the growth goals proposed by the student and some consideration to action if any difficulties are encountered. This growth feedback form is designed to be part of an ongoing process of learning and achievement growth, linking prior work to current work and projecting into future work.

\section{Personal Best Index}

There is also scope to provide informal feedback to students regarding their broader orientation to growth across a period of time (e.g., a school term) or through a task (e.g., a major assignment). The importance of feedback to students is well established (e.g., see Hattie, 2009) and therefore the potential merits of PB approaches may be further supported by incorporating a feedback dimension. Appendix D (Martin, 2012b) provides one example of a form that might be used to calculate a PB Index for an individual student. This particular form adopts a broad approach to growth, encouraging a PB in terms of achievement, engagement, and skills, as well as a Golden Point if the student has especially applied him/herself in that term or in that assignment. With little effort, this form could be adapted for some older students to score themselves, thereby promoting a greater self-regulatory emphasis in the task.

\section{Achievement Growth Assessment}

A more formal extension of the PB Index would be to map the growth of an individual's achievement across time. Importantly, the student's growth is assessed against his/her own prior growth (see Betebenner, 2008, 2009). Indeed, promising 
findings for students with ADHD have been identified for self-graphing academic progress (Figarola et al., 2008). The rate of growth may be colour coded, with green indicating commendable growth, yellow indicating stability, and red indicating decline. Consistent with Betebenner (2008, 2009), the final part of the chart may project into the future with three coloured possibilities clearly indicated: a green future projection would indicate the outcome following exceptional effort, attitude and educational support, a yellow future projection would indicate the outcome following modest effort, attitude and educational support, and a red future projection would indicate the outcome following poor effort, attitude and educational support. Thus, the student can see what future outcomes are possible given the quality of their effort, application and educational support. Although apparently straightforward, there are some important considerations to conduct this form of assessment reliably and validly. For example, it is essential that the scale of measurement at each time point is developmentally comparable so that true growth is detectable. High quality tests and assessment are essential for measuring and demonstrating achievement growth.

\section{Conclusion}

Alongside other successful evidence-based interventions for students with ADHD such as medication, structured and scaffolded learning, and direct instruction (Barkley, 2006), PB goals represent a potentially useful inclusion in their learning and instruction. ADHD is not systematically correlated with intelligence; thus intelligence is not a barrier for students with ADHD any more than it is a barrier for students without ADHD. It is therefore important to identify cognitive and behavioural interventions that can help students with ADHD develop and maintain positive academic trajectories that are comparable to the academic trajectories of students without ADHD. Latest research shows that PB goals may be one of these interventions.

\section{Acknowledgments}

Thanks are extended to the Australian Research Council for funding.

\section{References}

American Psychiatric Association. (2000). Diagnostic and statistical manual of mental disorders, revised. Washington, DC: Author.

Anderman, E., Anderman, L., Yough, M., \& Gimbert, B. (2010). Value-added models of assessment: Implications for motivation and accountability. Educational Psychologist, 45, 123-137.

Anderman, E.M., \& Wolters, C.A. (2006). Goals, values, and affect: Influences on student motivation. In P.A. Alexander \& P. Winne (Eds.), Handbook of educational psychology (pp. 369-389). Mahwah, NJ: Erlbaum.

Barkley, R.A. (Ed). (2006). Attention-deficit hyperactivity disorder: A handbook for diagnosis and treatment. New York: Guilford Press.

Betebenner, D. (2008, June). Norm- and criterion-referenced student growth. Paper presented at CCSSO, Washington, DC. 
Betebenner, D. (2009). Growth, standards and accountability. Dover, NH: Center for Assessment.

Briggs, D., \& Betebenner, D. (2009, April). Is growth in student achievement scale dependent? Paper presented at the Annual Meeting of the National Council for Measurement in Education, San Diego, CA.

Brown, T.E. (2005). Attention Deficit Disorder: The unfocused mind in children and adults. New Haven, CT: Yale University Press.

Chandler, C. (2010). The science of ADHD. Oxford: Wiley-Blackwell.

Christenson, S., Reschly, A., \& Wylie, C. (Eds.). (2012). Handbook of research on student engagement. New York: Springer.

Covington, M.V. (2002). Rewards and intrinsic motivation: A needs-based developmental perspective. In F. Pajares \& T. Urdan (Eds.), Academic motivation of adolescents (pp. 1-27). Greenwich, CT: Information Age Publishing.

DuPaul, G.J., \& Stoner, G. (2003). ADHD in the schools: Assessment and intervention strategies (2nd ed.). New York: Guilford.

Dweck, C.S. (2006). Mindset: The new psychology of success. New York: Random House.

Elliot, A. (2005). A conceptual history of the achievement goal construct. In A. Elliot \& C. Dweck (Eds), Handbook of competence and motivation (pp. 52-72). New York: Guildford.

Figarola, P.M., Gunter, P.L., Reffel, J.M., Worth, S.R., Hummel, J., \& Gerber, B.L. (2008). Effects of self-graphing and goal setting on the math fact fluency of students with disabilities. Behavior Analysis in Practice, 1, 36-41.

Gray, J.A., \& McNaughton, N. (2003). The neuropsychology of anxiety: An enquiry into the function of the septo-hippocampal system. Oxford: Oxford University Press.

Harris, D.N. (2011). Value-added measures in education. Cambridge, MA: Harvard Educational Press.

Hattie, J. (2009). Visible learning: A synthesis of over 800 meta-analyses relating to achievement. London \& New York: Routledge, Taylor \& Francis Group.

Heiligenstein, E., Guenther, G., Levy, A., Savino, F., \& Fulwiler, J. (1999). Psychological and academic functioning in college students with attention deficit hyperactivity disorder. Journal of American College Health, 47, 181-185.

Liem, G.A., Ginns, P., Martin, A.J., Stone, B., \& Herrett, M. (2012). Personal best goals and academic and social functioning: A longitudinal perspective. Learning and Instruction, 22, 222-230.

Linnenbrink-Garcia, L., Tyson, D.F., \& Patall, E.A. (2008). When are achievement goal orientations beneficial for academic achievement? A closer look at moderating factors. International Review of Social Psychology, 21, 19-70.

Locke, E., \& Latham, G. (2002). Building a practically useful theory of goal setting and task motivation. American Psychologist, 57, 705-717.

Maehr, M.L., \& Zusho, A. (2009). Achievement goal theory: The past, present, and future. In K.R. Wentzel \& A. Wigfield (Eds.), Handbook of motivation at school (pp. 77-104). New York: Routledge.

Mariani, M., \& Barkley, R.A. (1997). Neuropsychological and academic functioning in preschool children with Attention Deficit Hyperactivity Disorder. Developmental Neuropsychology, 13, 111-129.

Martin, A.J. (2006). Personal bests (PBs): A proposed multidimensional model and empirical analysis. British Journal of Educational Psychology, 76, 803-825. 
Martin, A.J. (2012a). Attention-Deficit/Hyperactivity Disorder (ADHD), perceived competence, and self-worth: Evidence and implications for students and practitioners. In D. Hollar (Ed.), Handbook on children with special health care needs (pp. 47-72). New York: Springer.

Martin, A.J. (2012b). Personal best (PB) goal worksheets, personal best scoresheets, growth feedback forms, and learning growth charts. Sydney, Australia: Lifelong Achievement Group. Retrieved from www.lifelongachievement.com

Martin, A.J. (2012c). The role of Personal Best (PB) goals in the achievement and behavioral engagement of students with ADHD and students without ADHD. Contemporary Educational Psychology, 37, 91-105.

Martin, A.J. (in press). Academic buoyancy and academic outcomes: Towards a further understanding of students with ADHD, students without ADHD, and academic buoyancy itself. British Journal of Educational Psychology.

Martin, A.J., \& Liem, G.A. (2010). Academic Personal Bests (PBs), engagement, and achievement: A cross-lagged panel analysis. Learning and Individual Differences, 20, 265-270.

Purdie, N., Hattie, J., \& Carroll, A. (2002). A review of the research on interventions for Attention Deficit Hyperactivity Disorder: What works best? Review of Educational Research, 72, 61-99.

Rapport, M.D., Chung, K-M., Shore, G., \& Isaacs, P. (2001). A conceptual model of child psychopathology: Implications for understanding Attention-Deficit/ Hyperactivity Disorder and treatment efficacy. Journal of Clinical Child Psychology, 30, 48-58.

Ratey, N., \& Sleeper-Triplett, J. (2011). Strategic coaching for LD and ADHD. In S. Goldstein, J. Naglieri, \& M. DeVries (Eds.), Learning and attention disorders in adolescence and adulthood: Assessment and treatment. New York: Wiley.

Ryan, R.M., \& Deci, E.L. (2000). Self-determination theory and the facilitation of intrinsic motivation, social development, and well-being. American Psychologist, $55,68-78$.

Sergeant, J.A. (2005). Modeling Attention-Deficity/Hyperactivity Disorder: A critical appraisal of the cognitive-energetic model. Biological Psychiatry, 57, 1248-1255.

Sztajn, P., Confrey, J., Wilson, P-H., \& Edgington, C. (2012). Learning trajectory based instruction: Toward a theory of teaching. Educational Researcher, 41, 147-156.

Swanson, J., Posner, M., Cantwell, D., Wigal, S., Crinella, F., Filipek, P., ... Nalcioglu, O. (1998). Attention-Deficit/Hyperactivity Disorder: Symptom domains, cognitive processes, and neural networks. In R. Parasuraman (Ed.), The attentive brain (pp. 445-459). Cambridge, MA: MIT Press.

Vile Junod, R.E., DuPaul, G.J., Jitendra, A.K., Volpe, R.J., \& Cleary, K.S. (2006). Classroom observations of students with and without ADHD: Differences across types of engagement. Journal of School Psychology, 44, 87-104.

Vostanis, P. (2007). Mental health and mental disorders. In J. Coleman \& A. Hagell (Eds.), Adolescence, risk, and resilience, (pp.165-174). London: John Wiley.

Wilmhurst, L., Peele, M., \& Wilmhurst, L. (2011). Resilience and well-being in college students with and without a diagnosis of ADHD. Journal of Attention Disorders, $15,11-17$. 


\section{Appendix A Personal Best (PB) Goal Work Sheet}

(Reproduced with permission from Lifelong Achievement Group — visit www. lifelongachievement.com to download)

A PB is where you aim to match or better a previous best performance. It can be a mark you're aiming for or you can aim to do your schoolwork or study in a way that is an improvement on last time or the way you usually do it.

A. My $\mathrm{PB}$ is a mark in What mark are you aiming for?

OR

B. My PB is a better way of doing my schoolwork or study in

The better way of doing things is:

Is this $\mathrm{PB}$ maintaining a previous best or improving on a previous best? YES / NO If $\mathrm{NO}$, you need to develop a PB that does.

Do you believe you can reach this PB? YES / NO If NO, you need to develop a PB that you believe you can reach.

When do you plan to achieve this PB?

\begin{tabular}{|l|l|}
\hline Describe the steps involved in reaching your PB & $\sqrt{ }$ when achieved \\
\hline 1. First, I will & \\
\hline 2. Next, I will & \\
\hline 3. & \\
\hline 4. & \\
\hline 5. & \\
\hline 6. & \\
\hline 7. & \\
\hline 8. & \\
\hline 9. & \\
\hline 10. & \\
\hline
\end{tabular}

$\square$ I believe I reached my PB

$\square$ I think I just missed out

$\square$ I didn't get close to my PB My next PB is:
Evidence

Because

Because 


\section{Appendix B Learning Growth Chart}

(Reproduced with permission from Lifelong Achievement Group — visit www. lifelongachievement.com to download)

Name:

Subject: Topic:

Year: Class:

Date:

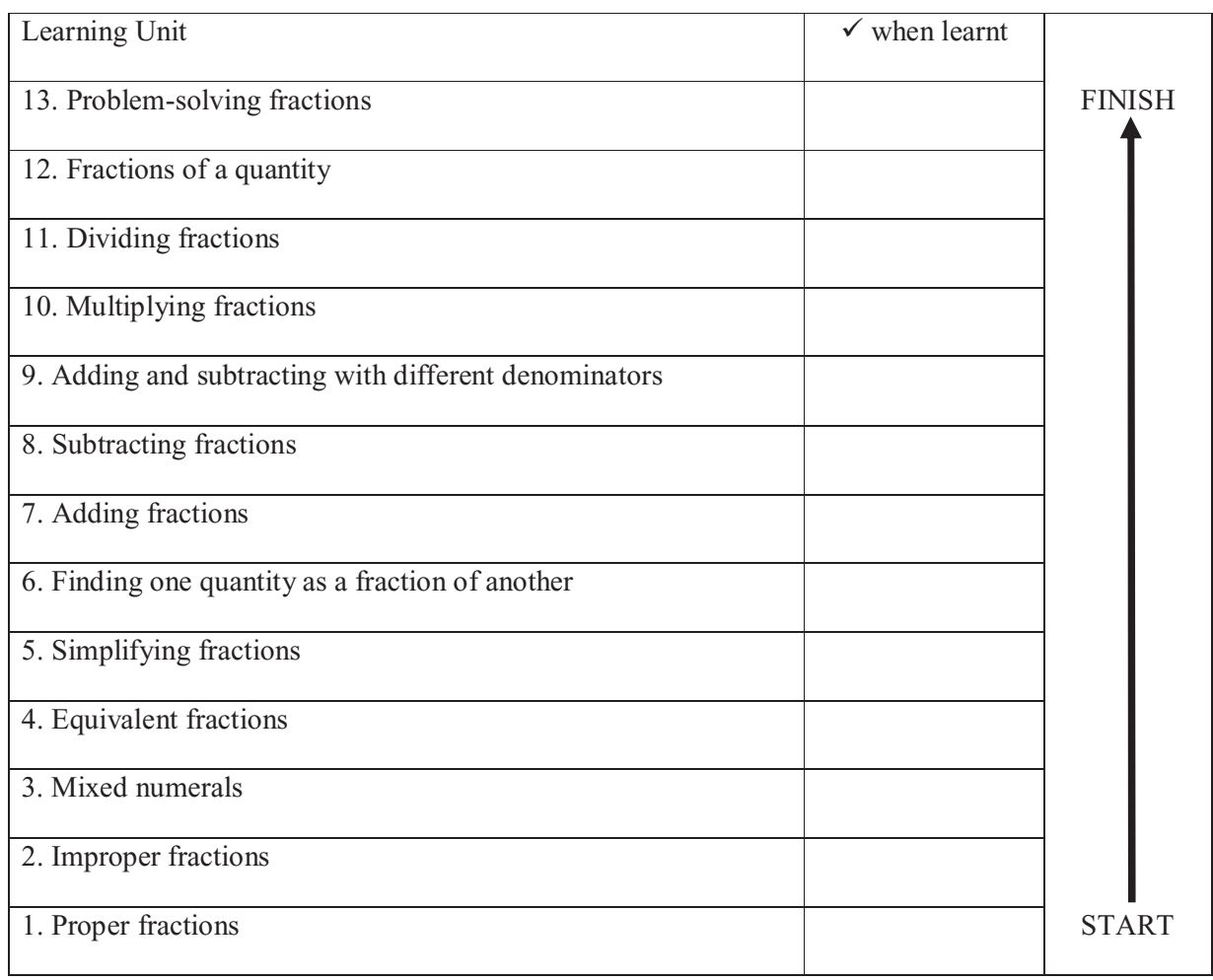


Appendix C

\section{Growth Goal Assignment Feedback Sheet}

Mark

(Reproduced with permission from Lifelong Achievement Group — visit www. lifelongachievement.com to download)

Student name:

Subject:

Class:

Assignment/Task name:

Central aims of assignment/task:

\begin{tabular}{|l|l|l|l|l|}
\hline Main criteria for assessment & $\begin{array}{l}\text { Could do } \\
\text { much better }\end{array}$ & $\begin{array}{l}\text { Satisfactory } \\
\text { work }\end{array}$ & $\begin{array}{l}\text { Good } \\
\text { work }\end{array}$ & $\begin{array}{l}\text { Excellent } \\
\text { work }\end{array}$ \\
\hline 1. & 1 & 2 & 3 & 4 \\
\hline 2. & 1 & 2 & 3 & 4 \\
\hline 3. & 1 & 2 & 3 & 4 \\
\hline 4. & 1 & 2 & 3 & 4 \\
\hline 5. Improvement on previous assignment/task (or maintains high standard) & 1 & 2 & 3 & 4 \\
\hline
\end{tabular}

Main strengths in student's work

1.

2.

3.

What to do for future improvement (or to maintain good work):

1.

2.

3.

\section{STUDENT GROWTH GOALS (student to complete)}

To improve (or to maintain my good work) in my next assignment/task I will:

1.

2 .

3.

In my next assignment/task, the mark I am aiming for is:

If I encounter difficulty in my next assignment/task, I will: 


\section{Appendix D \\ Personal Best (PB) Index}

(Reproduced with permission from Lifelong Achievement Group — visit www. lifelongachievement.com to download)

Name Year Class Date

This term's mark (circle one)

3 points Around or above previous best

2 points Slightly below previous best

1 point Well below previous best but put in reasonable effort to get this mark

0 points Well below previous best and put in little or no effort to get this mark

This term's enthusiasm/engagement/attitude (circle one)

3 points Around or above previous best

2 points Slightly below previous best

1 point Well below previous best but put in reasonable effort to get involved

0 points Well below previous best and put in little or no effort to get involved

Skills/competencies developed this term (circle one)

3 points Around or above previous best

2 points Slightly below previous best

1 point Well below previous best but put in reasonable effort to develop skills

0 points Well below previous best and put in little or no effort to develop skills

Golden point (circle if applicable to this student)

1 point This term this student was committed to personal excellence

PB Index

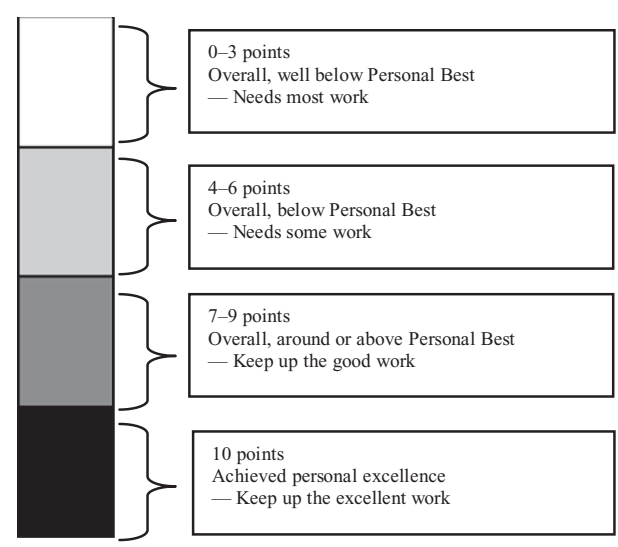

(Previous PB Index

/ 10)

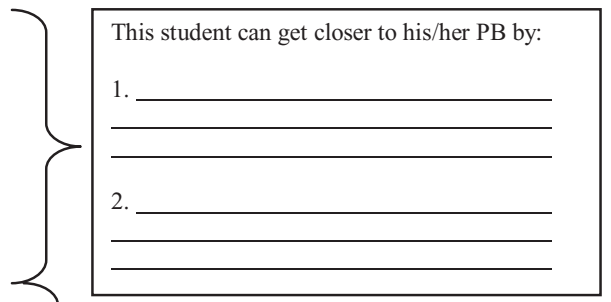

This student can sustain his/her PB by: 1.

2. 